Article

\title{
Global Economic and Food Security Impacts of Demand-Driven Water Scarcity-Alternative Water Management Options for a Thirsty World
}

\author{
Victor Nechifor * (D) and Matthew Winning \\ UCL Institute for Sustainable Resources, 14 Upper Woburn Place, London WC1H 0NN, UK; \\ m.winning@ucl.ac.uk \\ * Correspondence: victor.nechifor@ucl.ac.uk; Tel.: +44-(0)20-3108-9380
}

Received: 14 August 2018; Accepted: 9 October 2018; Published: 13 October 2018

\begin{abstract}
Global freshwater demand will likely continue its expansion under current expectations of economic and population growth. Withdrawals in regions which are already water-scarce will impose further pressure on the renewable water resource base threatening the long-term availability of freshwater across the many economic activities dependent on this resource for various functions. This paper assesses the economy-wide implications of demand-driven water scarcity under a 'middle-of-the-road' socio-economic development pathway by considering the trade-offs between the macroeconomic and food security impacts. The study employs a global CGE model comprising an advanced level of detail regarding water uses across economic activities and which allows for a sector-specific endogenous adaptation to water scarcity. A sustainable withdrawal threshold is imposed in regions with extended river-basin overexploitation (India, South Asia, the Middle East, and Northern Africa) whilst different water management options are considered through four alternative allocation methods across users. The scale of macroeconomic effects is dependent on the relative size of sectors with low-water productivity, the amount of water uses in these sectors, and the flexibility of important water users to substitute away from water inputs in conditions of scarcity. The largest negative GDP deviations are obtained in scenarios with limited mobility to re-allocate water across users. A significant alleviation is obtained when demand patterns are shifted based on differences in water productivity, however, with a significant imposition on food security prospects.
\end{abstract}

Keywords: computable general equilibrium; water allocation; water scarcity; food security; hydroeconomic assessment; virtual water

\section{Introduction}

As most countries aspire to continued economic development, water demand may also sustain the upward trend in human withdrawals observed in the past century. Thus far, irrigation has been the most important driver in the expansion of global freshwater withdrawals. Nevertheless, other sectors have also played a significant role, notably in industrialised countries, e.g., water for power plant cooling in the US and Europe [1]. The same tendency may occur in developing regions as their prosperity growth becomes more reliant on energy inputs and other water-intensive commodities. Growth in population and urbanisation rates in these countries would also put additional pressure on freshwater resources through higher municipal water demand by households. Global non-agricultural water uses are thus projected to grow fourfold for manufacturing and to more than double for thermal cooling and municipal uses [2], with a higher expansion to occur notably in emerging economies [3].

With significant differences in the distribution of water endowments across world regions, the likely expansion in water demand in water-scarce areas will lead to generalised and more frequent 
imbalances between demand and supply. The implications of disruptions to economic activities may be large-scale $[4,5]$ and could affect all sectors and households either directly through a reduction in water availability due to increased competition among users or indirectly through a reduction in the supply of water-intensive commodities. As supply chains become increasingly integrated globally, the impacts could also be felt outside these regions through international trade.

Regions which are currently capping withdrawals to avoid river-basin overexploitation generally do so by prioritising user groups based on historical patterns which are largely conducive to economic inefficiencies [6]. Although water trade is permitted both formally and informally [7] in many instances, the exchange of water withdrawal rights remains limited with restrictions stemming from government intervention and limited conveyance capacity. Therefore, while full water mobility across large geographical areas could be hindered by the involved costs related to conveyance infrastructure, institutions, and use rights transactions, water use efficiency could still be improved through the consideration of market-based allocation means.

There are now many studies projecting the size of future demand in the face of socio-economic development [3,8-13]. However, the measurement of the economy-wide impacts of water shortages stemming from the gap between a growing demand and a limited freshwater supply is still at an incipient stage. Most economic modelling has been dedicated to the analysis of water scarcity in relation to crop production [14-20]. In these studies, the exclusion of the direct effects of water deficits over households and sectors outside agriculture leads to an understatement of the economic impacts of water scarcity and does not allow for a discussion on alternative economy-wide water management options to alleviate these effects. At the same time, the few assessments of the macroeconomic impacts of water scarcity [21,22] were either single-year (comparative statics) or with limited elements in considering the relationship between socio-economic development and water demand. Only the recent attempt in [23] tackled the link between socio-economic development and economy-wide water deficits, and the importance of water productivity in the resource allocation across sectors in conditions of constrained water availability. Nevertheless, the study uses a rather prescriptive water allocation rule as water remains an implicit factor of production. Therefore, an endogenous adaptation of economic sectors to water scarcity based on the shadow price of water is not possible.

The present paper aims to expand the evidence on the economic and food security impacts of allocation rules based on water productivity calculated on a withdrawal basis and an explicit water shadow price determined at an economy-wide level. The analysis is conducted by integrating into one global macroeconomic modelling framework (RESCU-Water) the economy-wide impacts of demand-driven water scarcity by considering a wide range of water users and water allocation methods. The model scenarios are applied to four regions (India, South Asia, the Middle East, and Northern Africa) which are already facing extensive river basin over-exploitation $[24,25]$ and for which the water demand structure is expected to evolve significantly towards more non-agricultural uses in the coming decades. Therefore, the use of a global assessment allows for the consideration of water scarcity occurring simultaneously across large geographical areas. Furthermore, water-abundant regions can also expand their water withdrawals to take advantage of their competitive advantage through international trade. The effects of population and economic growth on a baseline water demand are broken down by user type through distinct demand patterns. These unconstrained demand calculations based on the 'middle of the road' SSP2 socio-economic development scenario [26] are used to calibrate the RESCU-Water model for water scarcity simulations in the 2004-2050 horizon. Regions with excess water demand relative to a sustainable water supply threshold need to reduce withdrawals and implicitly re-allocate water across economic sectors based on alternative rules for user prioritisation. 


\section{Materials and Methods}

\subsection{Economy-Wide Modelling of Water Uses}

The assessment employs an updated version of the RESCU-Water model [27] by specifying water as an explicit factor of production across the different economic activities. The model is based on global dynamic-recursive computable general equilibrium (CGE) framework comprising 20 world regions and 31 productive activities (see Supplementary Material) and uses the GTAP9-Power database [28]. Under a policy scenario, starting from the base case equilibrium, CGE models adjust price and quantity variables across all factor and commodity markets within an economy such that supply and demand in each market are equal, costs of production are minimised and household utility is maximized. The model solution thus captures a state of allocative efficiency not just in relation to water resources use but to the employment of all factors of production (capital, labour, and land). Therefore, compared to water partial equilibrium models, where many price variables entering the specification of production technologies are exogenous, the RESCU-Water model includes the price effects on all production inputs sourced from both the domestic market and from imports.

The inclusion of water in the model is implemented on a withdrawals basis given that, in practice, payments for water use rights are made based on abstracted rather than on consumed volumes. For instance, the measurement of consumed volumes through evapotranspiration in irrigated agriculture may prove to be technically impossible. Water uses are represented through a distinction between self-abstracting industries (SAI) which use water as a raw natural resource (water as an endowment) and supplied industries and households which employ water as a commodity. This separation allows for the accounting of treatment and distribution costs of supplied water to industrial and municipal users distinctly from the scarcity value of water through abstraction.

There are five SAI typologies making use of the regional water resource base-industrial water supply, municipal water supply, thermal power (for cooling), livestock (for drinking), and irrigated crops (Figure 1). The first two further distribute water as a supplied commodity to the downstream sectors and households, whereas the other three use water resources in the production of non-water market commodities.

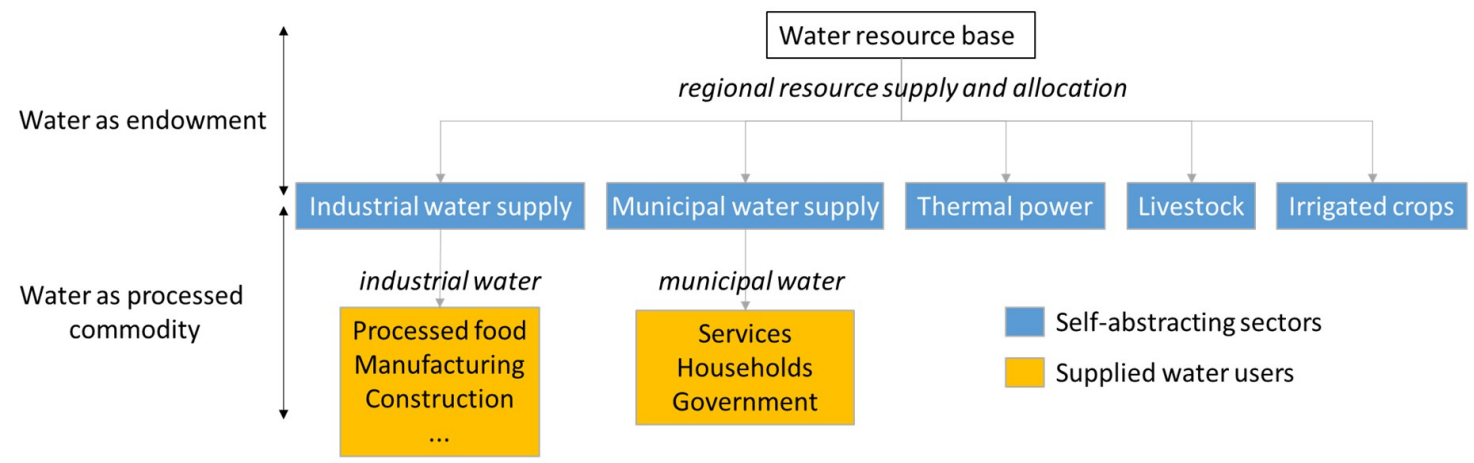

Figure 1. Water classification in the RESCU-Water model.

RESCU-Water comprises a bottom-up representation of crop production systems by considering eight crop classes with the production of each divided into the rainfed and irrigated growing methods. The technology used for irrigated crops in [27] was further developed through the addition of water endowments inputs as perfect complements to irrigation infrastructure and irrigable land (Figure 2, also see details on model equations in Supplementary Material). Under water scarcity, the substitution between rainfed and irrigated crops as well as the constrained intensification of other factors (capital and labour) in irrigated crop production leading to an improved field management allow for an attenuation of the adverse impacts of water deficits for irrigation. Land conversion occurs through a two-stage process. First, arable land is supplied using a logistic function which takes into account GAEZ land suitability limits from [29] for each modelled region. Second, arable land is 
attributed as irrigable or rainfed land through a constant elasticity of transformation function (CET) which accounts for yield differences between the two land types at a regional level obtained from [30].

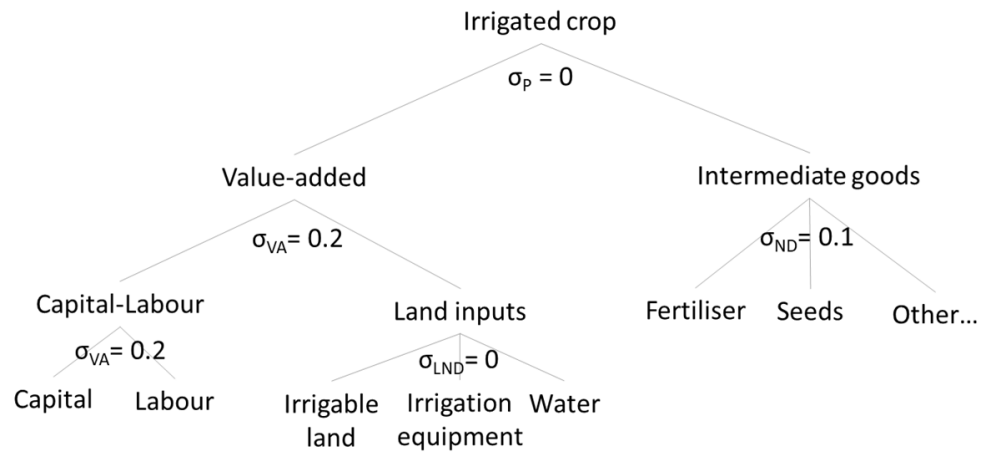

Figure 2. Production function of irrigated crops. The zero elasticity of substitution $\sigma_{\mathrm{LND}}$ specifies land-related inputs as perfect complements.

The use of water endowments by the other four SAI was introduced by assuming a zero elasticity of substitution with other inputs (Figure 3) i.e., a reduction in water availability for these users induces a proportional reduction in output. This specification is based on the reasonable assumption that water distribution networks cannot function without water resources, power plants cannot operate without cooling, and livestock cannot live without drinking water. The production costs of these sectors are composed of the scarcity value of water and that of value-added and intermediate inputs used. For water supply services (industrial and municipal), this structure enables the inclusion of the costs of water provision (treatment, routing, sewerage). Demand for supplied water is therefore influenced by both the water scarcity value and the regional cost recovery of water provision.

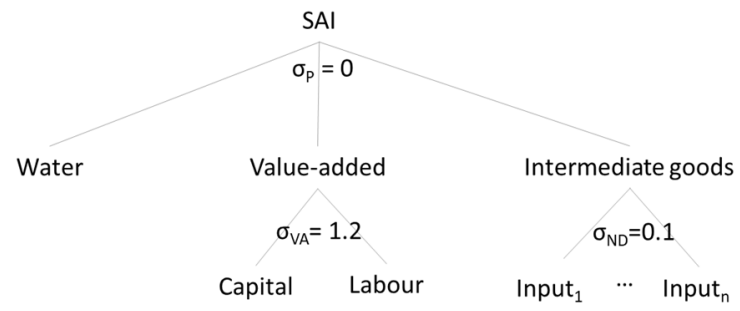

Figure 3. Production function of non-agricultural self-abstracting industries. The zero elasticity at the top-level indicates that production is not possible without water inputs.

The model also distinguishes between thermal and non-thermal power technologies allowing for an adaptation of power production to water scarcity through a substitution effect between the two electricity production varieties. In the 2004-2050 timeframe, the water intensity for thermal power production decreases to account for a gradual adoption of tower cooling as a more water efficient method. As for the downstream sectors, industrial water users are considered to have a low capacity to substitute away from supplied water inputs as these provide critical functions to their processes-dilution, frothing, suspension, etc. (see Supplementary Material). Municipal water users (services and households) have a higher flexibility in this regard by treating supplied water like any other commodity.

\subsection{Analysis of Water Scarcity under Different Water Management Regimes}

The modelling of water scarcity implies a reduction in water availability for economic activities in regions which either currently, or are projected to, exceed the levels of long-term sustainable water withdrawals. Water use projections across the 2004-2050 timeframe for the SSP2 storyline are undertaken by considering a range of drivers specific to each SAI e.g., GDP, population, industrial value-added and thermal power production (see Supplementary Material). In regions with long-term 
unsustainable withdrawals, the introduction of scarcity in the economic model is done by scaling down the water endowment availability from the supply levels required by the levels of unconstrained total demand to a region-specific sustainable withdrawals threshold $\left(S W T_{r}\right)$. This supply constraint leads to the occurrence of positive water shadow prices which guide the way freshwater resources are allocated throughout the economy.

Through an assumption of perfect mobility of water across economic sectors, the resource allocation under scarcity conditions is done such that the marginal productivity across water users is equal and that the shadow value of water is that of observable scarcity rents. Nevertheless, it is acknowledged that perfect mobility is difficult to be obtained as this would require the existence of economy-wide water markets with the implied existence of institutional capacity to enforcing water rights and the intra- and inter-basin routing infrastructure. At the same time, norms and values influencing people's and subsequently decision-makers' sensitivity to environmental degradation are also important non-market determinants in the management of water resources [31]. Therefore, the model allows alternative assumptions for water mobility and user prioritisation through the introduction of different allocation mechanisms:

(1) Limited mobility (LIMIT) - only a fraction of 5\% of total water resources can be re-allocated across users based on scarcity price information.

(2) Agriculture-last (AGLST) - only the use of irrigation water is constrained whilst non-crop users are free-riders.

(3) Full allocation (FULL) — the existence of one single water market within a region in which all water resources are tradeable between any given self-abstracting sectors.

(4) Fragmented markets (FRAGM) - water withdrawals for crops and non-crop sectors are completely separated, and the reduction in water availability for each is proportional to the overall required reduction in unconstrained withdrawals.

The first method (LIMIT) assumes a reduced degree of mobility of water resources across the wider economic sectors. The assumption behind this market arrangement is that some trade can occur between large water users enabling high-value activities to compensate for low-value activities for freeing up water resources, however, re-allocation remains limited. The second method is implicit in most water scarcity modelling $[14-16,18,19]$ and uses the assumption that agriculture is the user with the lowest priority. Water availability for irrigation is thus determined once all other unconstrained water withdrawals have been deducted from the total sustainable supply. The third method (FULL) implies that one single water market price applies to all users at a regional level. Although examples of economy-wide trading of water rights do not currently exist, this method serves as a benchmark for water allocative efficiency. The fourth method (FRAGM) implies an allocation by separating water allocative efficiency across crop types from that across non-crop sectors. This method is also used in [32] and enables a guaranteed volume of water available to irrigated crop production.

Water re-allocation across all these methods is based to different extents on the water scarcity rents-even in the LIMIT case, the mobile 5\% volumes of water are allocated based on differences in water productivity across users. However, in reality, there will be transactional costs involved by the trading of water user rights. These were not included in this analysis, given the uncertainty regarding the institutional setup required to enable such transactions.

Table 1 presents the water demand projections in the four water-scarce regions together with the SWT imposed in the model simulations (see Supplementary Material on the calculation of the $S W T_{r}$ values and the projections of future water demand by region and by user type). The threshold values correspond to a share of current total renewable water resources (TRWR) in each region-40\% for India, 80\% for South Asia and Northern Africa, 100\% for the Middle East. For India, in line with the widely used 'withdrawals to availability' indicator developed in [33], the $40 \%$ is a marker of severe water stress and is relevant here considering the extensive river basin exploitation at current withdrawals representing just 35\% of TRWR. For the Middle East, 100\% of the TRWR threshold comes from the 
infeasibility in finding a model solution in the AGLST scenario for lower threshold values. The 2050 sustainability curtailment represents thus $28 \%$ of unconstrained withdrawals for India, $30 \%$ for South Asia, 29\% for the Middle East, and 15\% for Northern Africa.

Table 1. Unconstrained water demand evolution and sustainable withdrawal thresholds (in $\mathrm{km}^{3}$ ).

\begin{tabular}{|c|c|c|c|c|c|c|c|c|c|c|c|c|c|c|}
\hline \multirow{2}{*}{ Region } & \multicolumn{2}{|c|}{ Irrigation } & \multicolumn{2}{|c|}{ Livestock } & \multicolumn{2}{|c|}{$\begin{array}{l}\text { Thermal } \\
\text { Cooling }\end{array}$} & \multicolumn{2}{|c|}{ Industrial } & \multicolumn{2}{|c|}{ Municipal } & \multicolumn{2}{|c|}{ Total } & \multirow{2}{*}{$\begin{array}{l}2050 \\
\text { SWT }\end{array}$} & \multirow{2}{*}{$\begin{array}{l}2050 \text { Required } \\
\text { Reduction }\end{array}$} \\
\hline & 泣 & No & $\underset{\perp}{\tilde{D}}$ & $\begin{array}{l}\text { No } \\
\text { ỗ }\end{array}$ & 柿 & N & 泣 & No & 产 & No & 舒 & No & & \\
\hline India & 599.6 & 783.5 & 2 & 2.4 & 10 & 30.1 & 30.7 & 173.2 & 20.7 & 61.6 & 662.9 & 1050.8 & 758.7 & 292.1 \\
\hline South Asia & 301.3 & 299 & 0.2 & 0.3 & 5.3 & 6.2 & 2.6 & 8 & 6.8 & 18.3 & 316.2 & 331.8 & 232 & 99.8 \\
\hline Middle East & 240 & 263 & 1.4 & 2.3 & 37.1 & 34.9 & 23 & 48.2 & 100.9 & 221.5 & 402.3 & 569.9 & 402.3 & 167.6 \\
\hline Northern Africa & 166.3 & 191.2 & 1.4 & 2.3 & 0 & 0 & 1.4 & 2.3 & 3.1 & 6.2 & 172.2 & 202 & 172.2 & 29.8 \\
\hline
\end{tabular}

\section{Results}

\subsection{Economic Output Impacts}

The economic impacts of water scarcity are experienced at an aggregate level mostly in water-scarce regions (Table 2), with only minor influences for the other regions. Nevertheless, by 2050, the negative impacts over world GDP measured in real terms could be in the order of $0.15 \%$, or over $\$ 130$ bn GDP losses under the more inflexible water allocation regimes (LIMIT and FRAGM). The macroeconomic impacts are reduced by two-thirds under the assumption of economy-wide water trading (FULL case) and are further reduced to negligible levels under the AGLST regime. This finding is an indication that greater GDP impacts are obtained with increased constraints on the water availability to non-agricultural sectors. The improved results under AGLST also indicate that constraining the economic activity in agriculture frees up other factors of production (capital and labour) for the rest of the sectors, increasing the productivities of these factors compared to the FULL scenario.

Compared to the GDP reductions, the welfare impacts of water deficits are considerably lower in water-scarce regions in the LIMIT, FULL and FRAGM cases. Depending on the incidence of scarcity over the different economic sectors, consumer prices can decrease leading even to positive equivalent variation (EV) outcomes (India-FRAGM, South Asia-AGLST). In the other regions, the impacts turn from positive GDP to negative EV as domestic prices of water-intensive commodities increase due to the expansion of foreign demand.

In water-scarce regions, the incidence of the allocation regimes is dependent on the regional unconstrained water demand patterns in the baseline. The largest impacts in all four regions are obtained in the LIMIT variant (Figure 4), with the highest GDP deviations in the Middle East and South Asia. The FRAGM regime produces similar results to LIMIT in India and the Middle East; as opposed to the other two regions, non-irrigation water demand consistently increases its weight in overall withdrawals by 2050, and therefore the requirement for more flexibility in water re-allocation away from irrigation becomes more stringent. The AGLST method, affecting mostly crop production, leads to low GDP impacts except for South Asia where food sectors continue to have an important weight in the economy. Northern Africa is generally unaffected by water scarcity given the dominant role of irrigation in overall withdrawals persisting in 2050-small volumes of water reallocation even within the mobility limits of the LIMIT case (5\% of total supply) are sufficient to ensure the resilience to water shortages of the economy as a whole. Therefore, there are important differences in the incidence of water scarcity between the first three (India, South Asia, and the Middle East) and this region. 
Table 2. Real GDP and equivalent variation impacts by region in 2050. The equivalent variation (EV) represents the equivalent change in household income at constant prices that would produce the same welfare effects as the change in prices obtained through the model simulations.

\begin{tabular}{|c|c|c|c|c|c|c|c|c|c|c|c|c|}
\hline \multirow[b]{2}{*}{ Region } & \multicolumn{3}{|c|}{ LIMIT } & \multicolumn{3}{|c|}{ AGLST } & \multicolumn{3}{|c|}{ FULL } & \multicolumn{3}{|c|}{ FRAGM } \\
\hline & $\begin{array}{c}\text { RGDP } \\
(\%)\end{array}$ & $\begin{array}{l}\text { RGDP } \\
\text { (\$bn) }\end{array}$ & $\begin{array}{c}\text { EV } \\
\text { (\$bn) }\end{array}$ & $\begin{array}{c}\text { RGDP } \\
(\%)\end{array}$ & $\begin{array}{l}\text { RGDP } \\
\text { (\$bn) }\end{array}$ & $\begin{array}{c}\text { EV } \\
\text { (\$bn) }\end{array}$ & $\begin{array}{c}\text { RGDP } \\
(\%)\end{array}$ & $\begin{array}{c}\text { RGDP } \\
\text { (\$bn) }\end{array}$ & $\begin{array}{c}\text { EV } \\
\text { (\$bn) }\end{array}$ & $\begin{array}{c}\text { RGDP } \\
(\%)\end{array}$ & $\begin{array}{c}\text { RGDP } \\
\text { (\$bn) }\end{array}$ & $\begin{array}{c}\text { EV } \\
\text { (\$bn) }\end{array}$ \\
\hline Middle East & $(1.797)$ & $(89.04)$ & $(10.76)$ & $(0.020)$ & $(0.97)$ & (3.07) & $(0.761)$ & $(37.71)$ & $(9.71)$ & $(1.841)$ & (91.22) & (15.69) \\
\hline South Asia & (1.606) & $(7.07)$ & $(1.51)$ & $(0.562)$ & $(2.47)$ & 0.13 & $(0.530)$ & $(2.33)$ & $(0.10)$ & $(0.554)$ & $(2.44)$ & $(0.63)$ \\
\hline India & $(0.435)$ & $(33.19)$ & $(7.80)$ & $(0.029)$ & $(2.24)$ & $(3.53)$ & $(0.148)$ & (11.26) & $(0.96)$ & $(0.465)$ & (35.43) & 5.11 \\
\hline Northern Africa & $(0.022)$ & $(0.29)$ & $(0.63)$ & $(0.003)$ & $(0.04)$ & $(0.05)$ & $(0.012)$ & $(0.16)$ & $(0.01)$ & $(0.010)$ & $(0.14)^{\prime}$ & $(0.44)$ \\
\hline Central Asia & $(0.016)$ & $(0.04)$ & 0.00 & $(0.001)$ & $(0.00)$ & $(0.03)$ & (0.003) & $(0.01)$ & $(0.02)$ & $(0.006)$ & $(0.01)$ & $(0.05)$ \\
\hline Eurasia & $(0.009)$ & $(0.12)$ & 0.05 & $(0.000)$ & $(0.00)$ & $(0.02)$ & $(0.002)$ & $(0.03)$ & $(0.02)$ & $(0.006)$ & $(0.07)$ & $(0.10)$ \\
\hline China & $(0.002)$ & $(0.30)$ & $(0.51)$ & 0.000 & 0.05 & $(0.16)$ & $(0.001)$ & $(0.11)$ & $(0.28)$ & $(0.004)$ & $(0.50)$ & $(0.62)$ \\
\hline Southeast Asia & $(0.002)$ & $(0.06)$ & $(0.58)$ & 0.003 & 0.10 & $(0.28)$ & 0.000 & 0.00 & $(0.36)$ & $(0.005)$ & $(0.16)$ & $(0.61)$ \\
\hline Northern Europe & $(0.002)$ & $(0.19)$ & 0.33 & 0.000 & 0.05 & $(0.05)$ & $(0.000)$ & $(0.03)$ & $(0.09)$ & $(0.002)$ & $(0.23)$ & 0.06 \\
\hline Southern Europe & $(0.001)$ & $(0.05)$ & $(0.12)$ & 0.001 & 0.08 & $(0.29)$ & $(0.000)$ & $(0.01)$ & $(0.15)$ & $(0.002)$ & $(0.18)$ & $(0.12)$ \\
\hline Northeast Asia & $(0.000)$ & $(0.00)$ & 0.07 & 0.002 & 0.09 & 0.05 & 0.000 & 0.02 & $(0.02)$ & $(0.002)$ & $(0.09)$ & $(0.11)$ \\
\hline USA & 0.000 & 0.04 & (1.19) & 0.001 & 0.25 & $(2.69)$ & 0.001 & 0.11 & (1.69) & $(0.000)$ & $(0.03)$ & (1.74) \\
\hline Sahel & 0.001 & 0.00 & $(0.04)$ & 0.000 & 0.00 & $(0.02)$ & $(0.001)$ & $(0.00)$ & $(0.03)$ & 0.002 & 0.00 & $(0.06)$ \\
\hline Canada & 0.000 & 0.01 & $(0.08)$ & 0.001 & 0.02 & $(0.08)$ & 0.001 & 0.01 & $(0.10)$ & 0.001 & 0.02 & $(0.19)$ \\
\hline North Latin Am & $(0.001)$ & $(0.04)$ & $(0.21)$ & 0.001 & 0.03 & (0.11) & 0.001 & 0.04 & $(0.23)$ & 0.002 & 0.10 & $(0.55)$ \\
\hline Australia \& NZ & 0.001 & 0.01 & $(0.01)$ & 0.003 & 0.06 & $(0.12)$ & 0.002 & 0.03 & $(0.10)$ & $(0.000)$ & $(0.01)$ & $(0.07)$ \\
\hline Southern Africa & 0.001 & 0.01 & $(0.09)$ & 0.008 & 0.07 & $(0.05)$ & 0.003 & 0.03 & $(0.05)$ & (0.003) & $(0.02)$ & $(0.07)$ \\
\hline Brazil & 0.002 & 0.02 & $(0.28)$ & 0.005 & 0.05 & $(0.47)$ & 0.003 & 0.03 & $(0.32)$ & 0.001 & 0.01 & $(0.30)$ \\
\hline South Latin Am & 0.005 & 0.03 & $(0.13)$ & 0.008 & 0.04 & $(0.23)$ & 0.004 & 0.02 & $(0.14)$ & 0.002 & 0.01 & $(0.10)$ \\
\hline Central Africa & $(0.006)$ & $(0.09)$ & $(0.34)$ & 0.016 & 0.25 & $(0.48)$ & 0.012 & 0.18 & $(0.54)$ & 0.009 & 0.14 & $(0.79)$ \\
\hline World & $(0.146)$ & (130.36) & $(23.84)$ & $(0.005)$ & $(4.60)$ & (11.57) & $(0.057)$ & (51.18) & (14.92) & $(0.146)$ & (130.26) & (17.07) \\
\hline
\end{tabular}

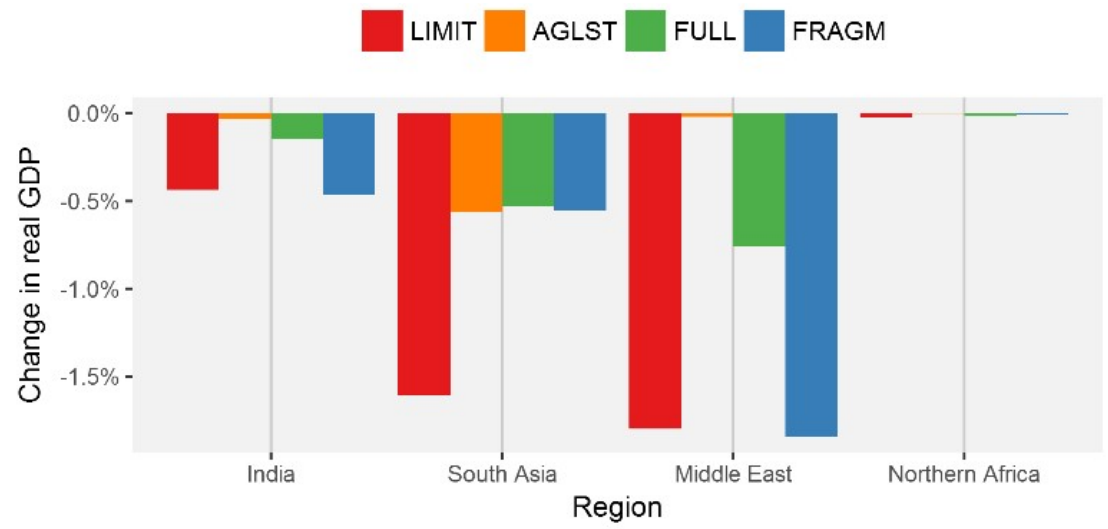

Figure 4. Real GDP impacts by region and by allocation method.

At a sectoral level, water scarcity impacts the activities with the highest dependency on water inputs given their substitution possibilities away from water use (Figure 5). Thus, crop production sees a drop of $5 \%$ or more in output in India, South Asia, and the Middle East with cascading effects over the processed food sector. As explored below, irrigated crop production drops by even higher rates with rainfed production only partially offsetting this effect. The same applies to the power generation sector-thermal electricity has the highest reduction in output of all activities, with the production mix switching towards non-thermal power.

Industrial sectors (chemicals, primary energy, mining, manufacturing, paper, and construction) are also affected but to a lower degree. The drop-in output for these sectors is highest for the LIMIT method with values up to $2 \%$ in the Middle East, $1 \%$ in India, and 3.5\% in South Asia. In the other water allocation methods, the output reduction is lower although still significant for the FRAGM method, negligible for FULL and even positive in some cases for AGLST. In Northern Africa, although the impacts of the different allocation regimes are generally negligible, industrial output increases in the LIMIT case with more mixed outcomes for the other methods. In the LIMIT regime, the limited flexibility to optimise water allocation within crop production across the different crop types determines an overall crop output reduction with a re-allocation of water resources to the non-crop sectors. 

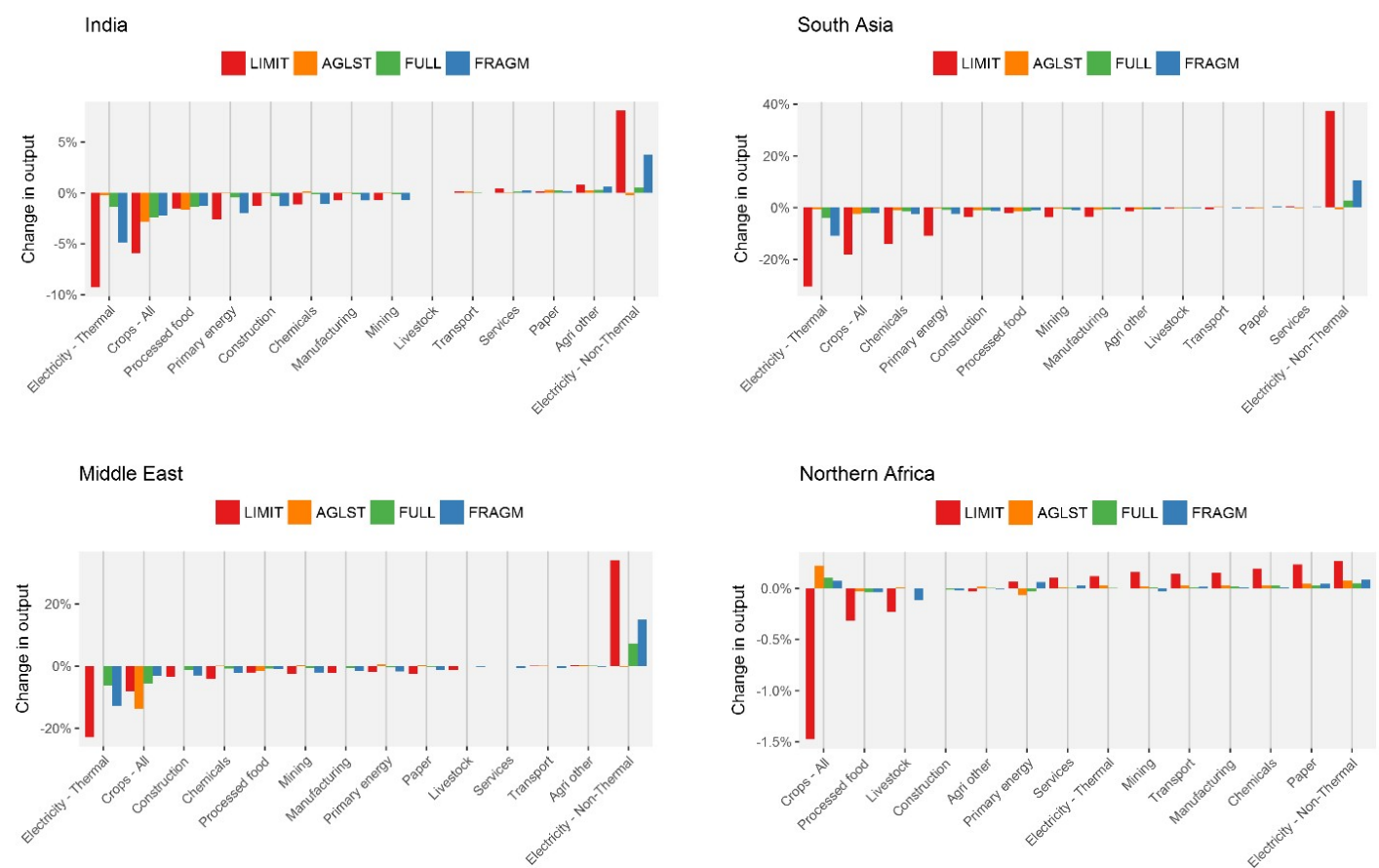

Figure 5. Sectoral output impacts in water-scarce regions.

\subsection{Water Scarcity Rents}

Water scarcity rents revealed by the market price of allocable water resources differ across methods (Table 3). The values obtained in the LIMIT case are the highest as the competition between users is limited by the low mobility of water endowments and are applicable only to the $5 \%$ water volumes which can be re-allocated. In the other water management regimes, water scarcity prices are much lower with the smallest values obtained in the FULL case. The values in this regime also represent the rents for the highest water allocative efficiency. For FRAGM, as irrigation and non-irrigation water uses are completely separated into two water markets, the price for irrigation uses are lower than those for non-irrigation. These differences mark the variation in marginal productivities between the two user types with possibilities of water re-allocation from crops to other non-agricultural sectors for further improvements in water allocative efficiency.

The AGLST case generates slightly higher rents than FULL, although the GDP impacts are lower. Despite the potential efficiency gains in re-allocating some water volumes from non-crop sectors, the decline in crop output due to water scarcity determines a shift of other means of production (capital and labour) to other sectors improving the economic outcomes of the overall factor allocation. Furthermore, as water scarcity rents are not reflected in the cost structure of non-crop sectors, these will have a further competitive advantage as free-riders by expanding their water uses beyond the levels from the FULL case.

Table 3. Water scarcity rents in 2050 by region and by allocation method $\left(\$ / \mathrm{m}^{3}\right)$

\begin{tabular}{cccccc}
\hline \multirow{2}{*}{ Region } & \multirow{2}{*}{ LIMIT } & \multirow{2}{*}{ AGLST } & \multirow{2}{*}{ FULL } & \multicolumn{2}{c}{ FRAGM } \\
\cline { 5 - 6 } & & & & Irrigation & Non-Irrigation \\
\hline India & 4.568 & 0.067 & 0.055 & 0.049 & 0.258 \\
South Asia & 4.460 & 0.042 & 0.040 & 0.037 & 0.129 \\
Middle East & 5.542 & 0.431 & 0.119 & 0.053 & 0.246 \\
Northern Africa & 0.962 & 0.003 & 0.003 & 0.003 & 0.064 \\
\hline
\end{tabular}

\subsection{Water Withdrawal Changes}

The changes in withdrawals by self-abstracting industries (and the changes in supplied water use by the underlying municipal and industrial water users) are determined by the trade-offs between these 
economic activities leading to different outcomes across the four allocation methods. Given the high water intensity of irrigated crops, the bulk of withdrawals reduction to reach the regional sustainability thresholds is ensured through a significant decrease in irrigation withdrawals (Figure 6). Nonetheless, for India and the Middle East, a noticeable demand cutback in volumetric terms also occurs in the second most important SAI-industrial water supply in India and municipal water supply in the Middle East.

In relative terms (change rate from baseline), despite a high water productivity, municipal water withdrawals in the LIMIT regime decrease at comparable rates with irrigation thus revealing the larger scope to reduce water demand of the underlying supplied users (services and households). In the FRAGM case, the higher flexibility in water allocation between non-crops users triggers a larger decrease in municipal water use to the benefit of the other sectors (thermal electricity, industrial water, and livestock). Furthermore, the single water market configuration (FULL case), determines a sharp reduction in water uses by irrigation and an increase in water availability for all other sectors (Middle East and South Asia) or notably for thermal electricity and municipal water (India). As baseline withdrawals for thermal electricity in Northern Africa are very low compared to other uses, water from irrigation is mainly redirected to industrial and municipal uses.

Changes in the water use patterns across the different crop types reflect the differences in crop water productivities. Thus, water demand is considerably reduced in water-intensive crops (see Supplementary Material). Withdrawals for rice and wheat in India decrease by more than $250 \mathrm{~km}^{3}(85 \%$ the equivalent of total required reductions) for wheat in South Asia by $60 \mathrm{~km}^{3}$ (60\% the total required reductions), for other crops in the Middle East by $40 \mathrm{~km}^{3}$ (a quarter of total required reductions) and for other crops in Northern Africa by $15 \mathrm{~km}^{3}$ (half as much as total required reductions).

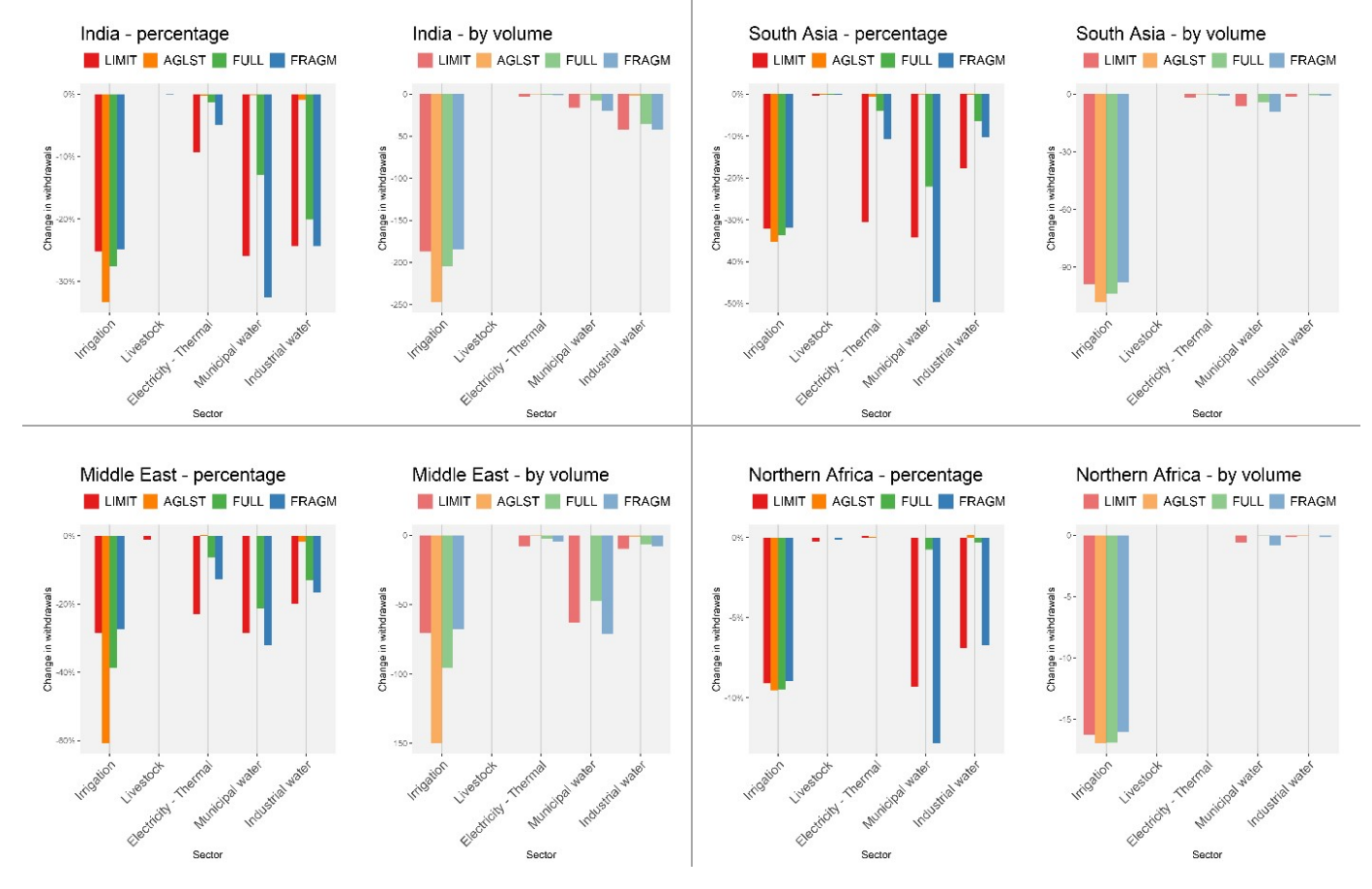

Figure 6. Withdrawal changes by region and by self-abstracting sector in relative and absolute terms.

\subsection{Food Security}

Water scarcity highly impacts crop production with some differences across crop types (Figure 7). In India, rice and wheat are affected the most with decreases in output of over 15\%; in South Asia, the same crops drop by more than 20\%; whereas, in the Middle East, other crops, fiber plants and wheat can have a decrease of more than 30\%. Northern Africa is less affected with only other crops having a marked decrease next to $10 \%$. To a large extent, the relationship between output and prices can be attributed to the household own-price demand elasticity (The household demand is specified in 
RESCU-Water as a linear expenditure system which comprises a subsistence and a disposable spending component. The own-price elasticity of demand on the disposable spending component is equal to 1 , while the subsistence part is updated with population changes). Nevertheless, other factors also come into play to explain the relative size of output and crop price changes-price elasticities of intermediate demand and those other final demand components (government, investment), inter-crop substitution through water re-allocation, the importance of imports in meeting domestic demand (import dependency) and the export share of domestic production.
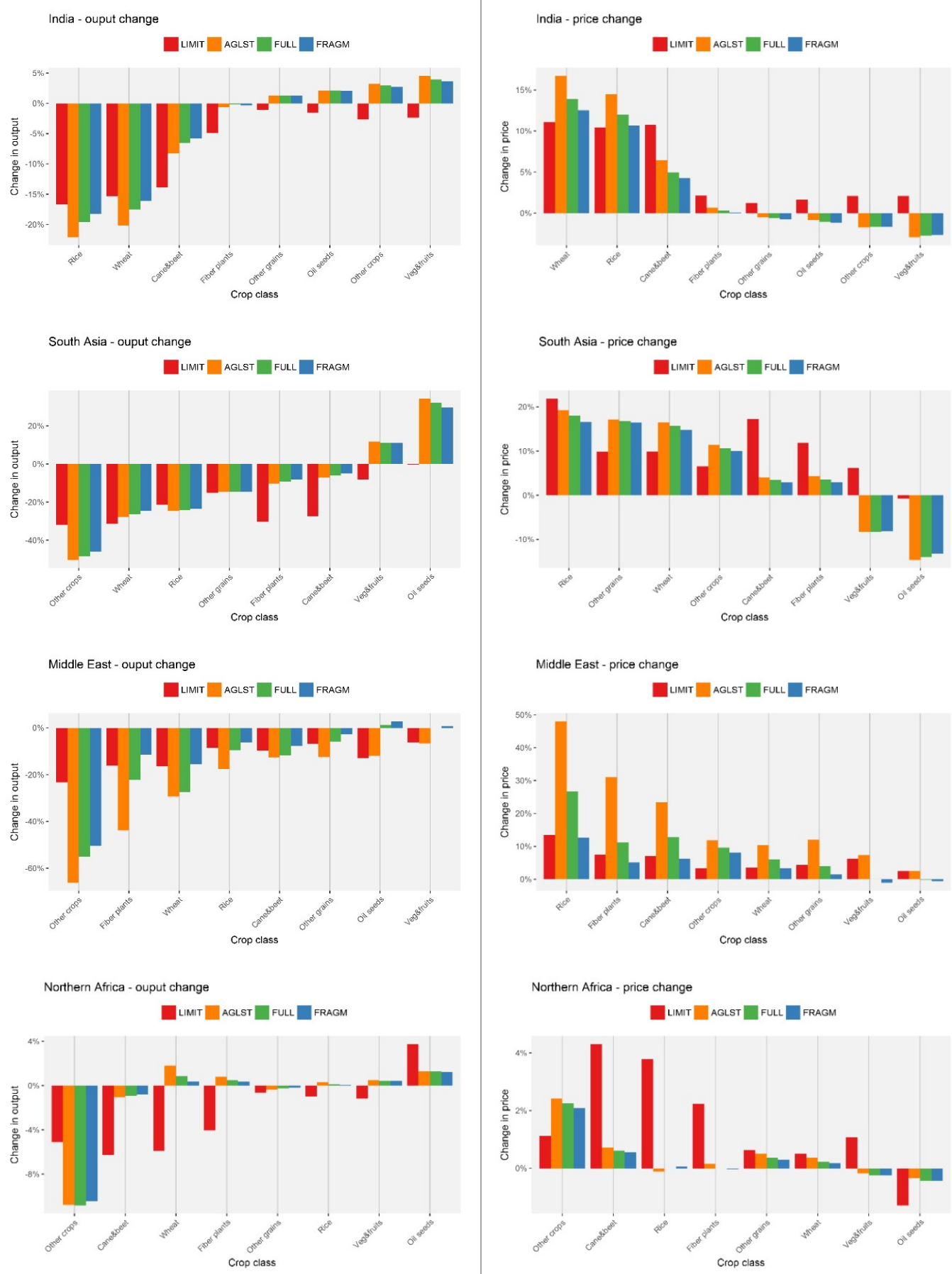

(a)

(b)

Figure 7. Water scarcity impacts on crop production. (a) Crop output change by region. (b) Crop price change by region. 
The incidence of water deficits is dependent on the water allocation method with a clear contrast between LIMIT and the other three variants. In this regime, crop production generally decreases across all crop types and regions, leading to an overall increase in crop market prices. Irrigated production is constrained by water deficits, similarly to all non-agricultural water users, and by the lack of flexibility to re-distribute water across crop types. Although the fall-back from irrigated to rainfed production is possible, the substitution between the two growing methods is not sufficient to fully counteract the drop in output of irrigated crops.

The other three allocation methods lead to a more noticeable re-allocation of water resources across crop classes marking the opportunity to improve the baseline water productivity of irrigation water. The scarcity impacts over the output of some crops are thus alleviated to the detriment of others. In India, rice and wheat production further decline in favour of additional water use and implicitly an output increase in all other crop types. In South Asia, the highest output decline occurs for other crops, wheat and rice. In Northern Africa, a significant decrease in production is obtained for other crops with limited negative impacts for cane and beet and other grains. In the Middle East, water is re-allocated from most crops to sustain the irrigated production of oil seeds and vegetables and fruits.

The largest contrast is obtained in the AGLST case where competition over water use between crop classes is exacerbated through the unrestricted withdrawals outside irrigation. As the water volumes available for crop production are the lowest among all four allocation methods, the differences in terms of water productivity between crop classes become more evident. The Middle East is the exception where trade-offs are limited due to a lower variation in the baseline water productivity levels across crop classes but also to international trade (see Section 3.5).

The water market fragmentation FRAGM offers some protection to crop production decline by limiting the volumes of water to be re-allocated to non-crop users. Hence the output and price outcomes are improved in FRAGM compared to the single market FULL case. The differences between the incidences of water scarcity across crop classes are also reduced. In this regard, AGLST and FRAGM could be considered two opposing allocation methods-the first overlooks the importance of crops and food security, whilst the latter imposes a volume available for irrigation in spite of differences between water productivities of specific crop classes and other water users.

In India, the effect of the decrease in domestic production over crop market prices is the most pronounced. This price response obtained across the four allocation methods is an indication that international trade does not have a significant role in reducing the food security impacts especially for the main crops of rice and wheat. As the imports dependency ratio in the baseline is low (see Supplementary Material), the Armington assumption for international trade through which the domestic and imported varieties are treated as imperfect substitutes prevents a significant expansion of imports despite the increase in market prices.

In contrast, imports in the Middle East and South Asia have an offsetting effect on prices. The import dependency of wheat in the Middle East grows from $24 \%$ in the baseline to $36 \%$ for AGLST, and from $9 \%$ to $43 \%$ for rice. Similarly, in South Asia, the dependency grows from $18 \%$ to $33 \%$ for rice. Imports of other crop classes also increase in importance-other crops in South Asia; oil seeds, fiber plants, other crops in the Middle East and other crops in Northern Africa. These are all cases for which the baseline dependency ratio is non-negligible and for which output is negatively affected by regional water deficits.

\subsection{Virtual Water Trade}

By using a multi-regional trade model as RESCU-Water, we explicitly consider the adjustments in trade patterns under water scarcity caused by changes in the opportunity costs and the comparative advantages in the production of commodities. The impacts of water use constraints on global virtual water trade are limited to the flows of the four regions and are mostly driven by crop trade (Figure 8). The largest changes occur in the Middle East, where the net imports grow by $26 \mathrm{~km}^{3}$ in the AGLST case, or 7\% of global virtual water trade in the baseline (global virtual water trade in 2050 for SSP2 is 
$372 \mathrm{~km}^{3}$ and includes the embedded water in both crop and non-crop traded commodities), indicating the importance of international trade in addressing the drop in domestic crop production in this region. This increase in imports converts the region from being a net exporter of water $\left(19 \mathrm{~km}^{3}\right.$ of net exports in the baseline) to a net importer $\left(8 \mathrm{~km}^{3}\right.$ of net imports in AGLST). In Northern Africa, although the changes are small in absolute terms $\left(1.5 \mathrm{~km}^{3}\right)$, these account for $10 \%$ total required reductions in withdrawals in the region. South Asia has a noticeable increase in net imports only in the LIMIT case determined by increased imports of vegetables and fruits and fiber plants. At the same time, some increases in net exports are obtained in India in the AGLST and FULL case, as a marker that international trade can further increase the impacts of water scarcity, notably over food security, through exports of water-intensive commodities stimulated by increases in foreign demand.
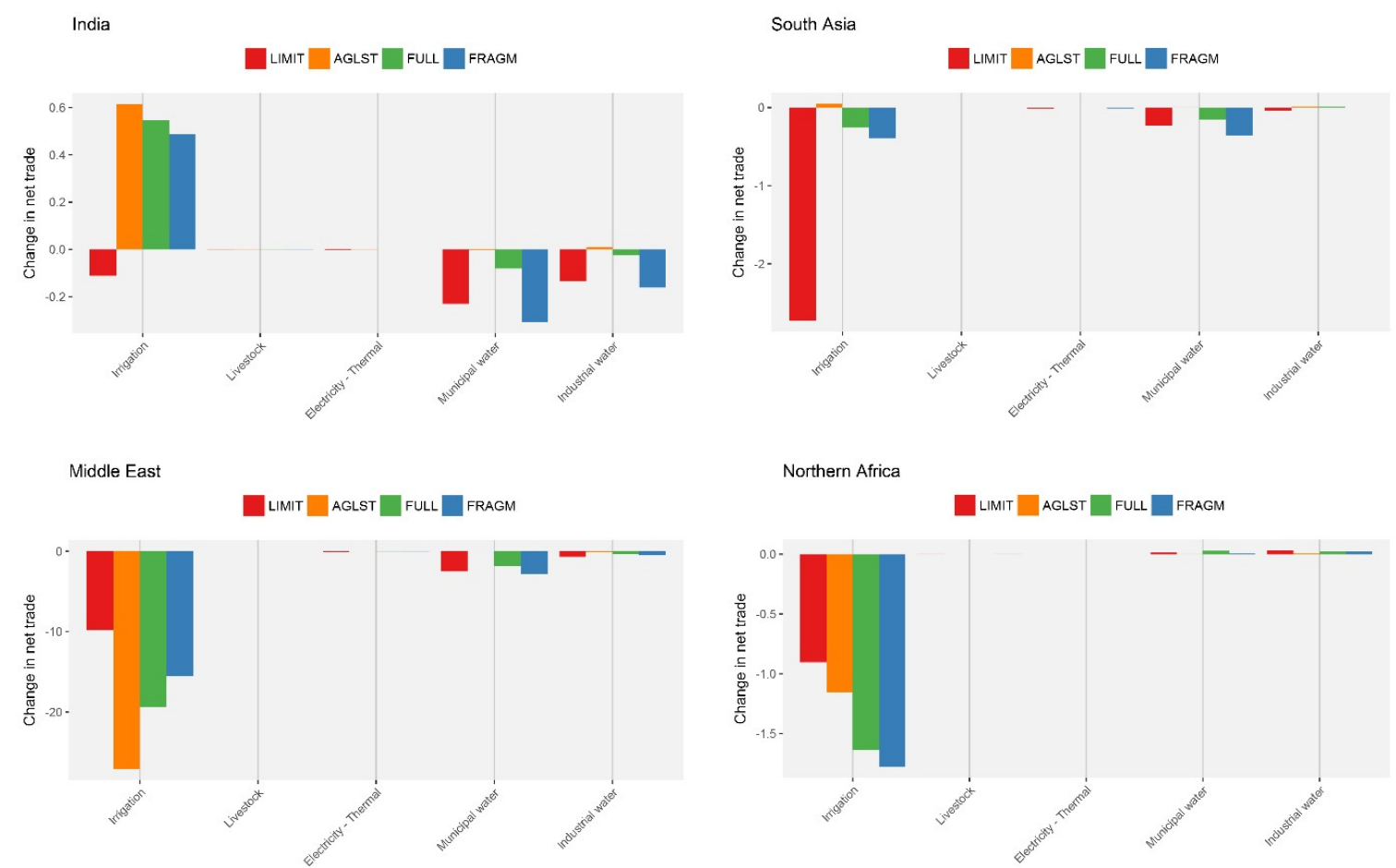

Figure 8. Changes in net trade of virtual water by water category (in $\mathrm{km}^{3}$ ).

Other visible changes in the net trade of virtual water outside crops are mainly linked to commodities from activities using industrial and municipal water. As expected, AGLST does not have any trade impacts given that water deficits do not constrain non-crop sectors. In the other allocation methods, virtual water trade associated with services (municipal water users) increases in all regions, except for Northern Africa, indicating international trade as a further adaptation mechanism to water scarcity. The same applies to the trade in commodities from industrial activities. However, the overall change in virtual water imports attached to industrial commodities is lower than that for services. Changes in the flows related to thermal electricity are limited by the low levels of electricity trade between regions in the baseline.

The Middle East has a dominant role in the virtual water trade changes with its net imports increasing across all its trading partners in all four allocation methods (Figure 9). The analysis of trade flows by pair also shows the importance of this region in the net trade of the other three water-scarce regions-most increases in virtual water exports of India, South Asia, and Northern Africa are absorbed by the Middle East.

Other important sources of virtual water include the USA, Southeast Asia, Central Africa, and Northern \& Southern Europe. Nevertheless, this growth in net exports of regions without water use constraints does not lead to a significant growth in water withdrawals in these regions-the total increase in 2050 in outside water-scarce regions is $2.8 \mathrm{~km}^{3}$ for LIMIT, $4.5 \mathrm{~km}^{3}$ for AGLST, $2.3 \mathrm{~km}^{3}$ 
for FULL and $2 \mathrm{~km}^{3}$ for FM. This low expansion is an indication that, instead of extending irrigated crop production, these regions either predominantly use rainfed production or are redirecting more domestic production towards exports.

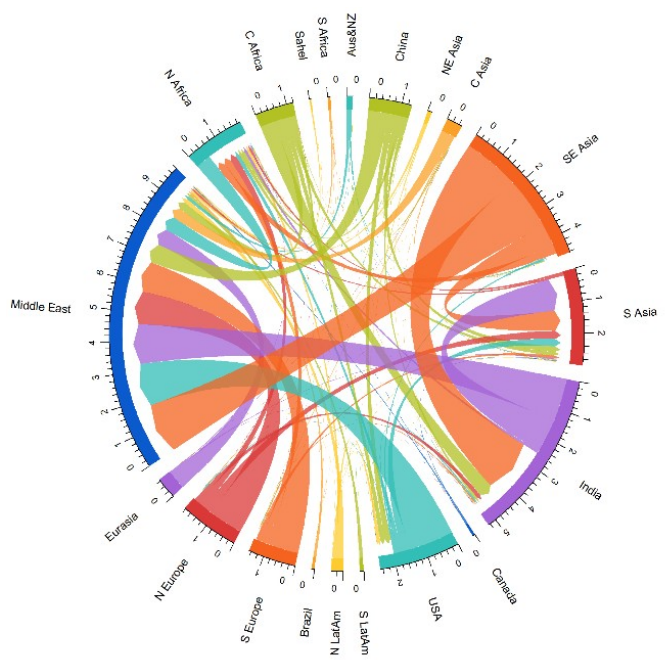

(a) LIMIT

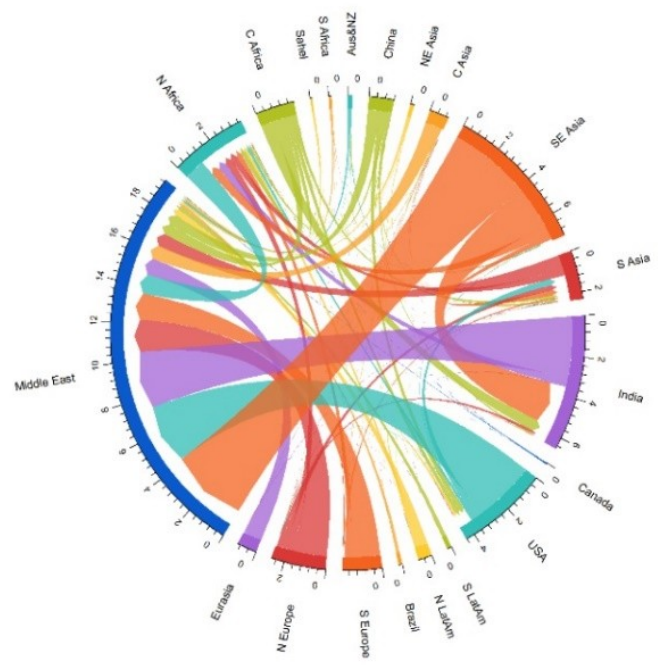

(c) FULL

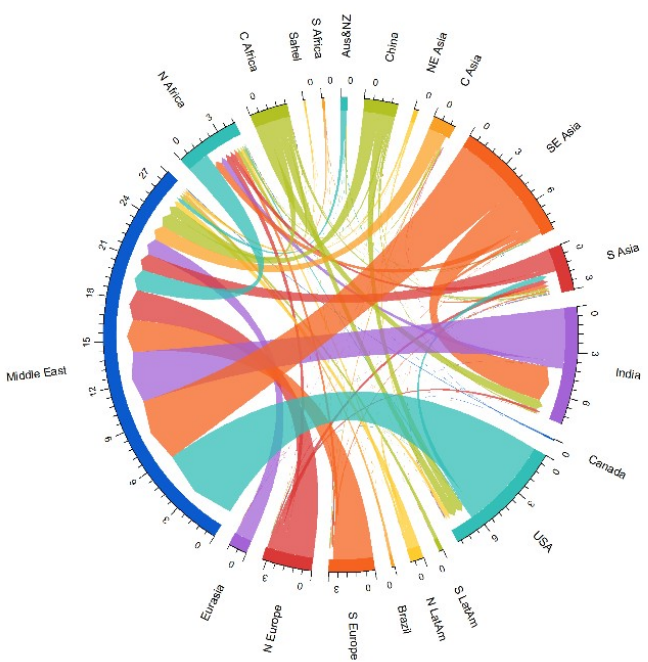

(b) AGLST

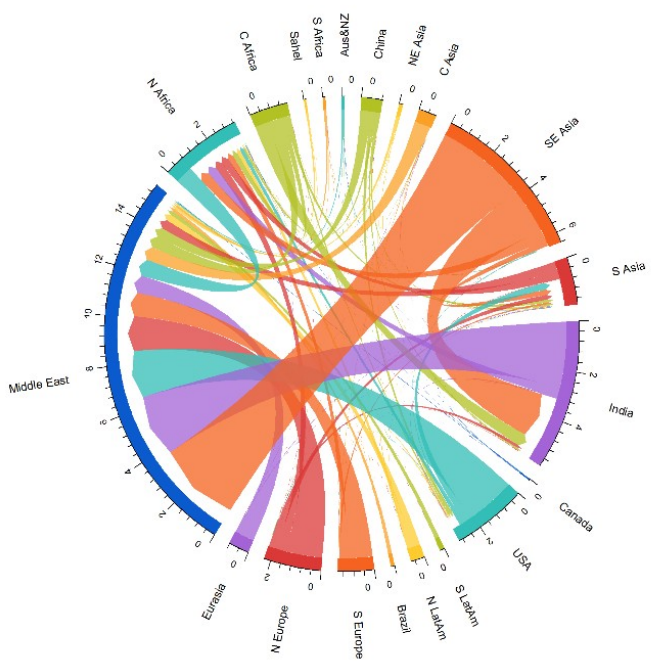

(d) FRAGM

Figure 9. Changes in virtual water trade flows of crops-(a-d) net values by trading pair (in $\left.\mathrm{km}^{3}\right)$ and by allocation method.

\section{Discussion}

The obtained results indicate different outcomes for economic activity, welfare and food security across the four allocation methods considered. In essence, the LIMIT method leads to the highest impacts across all sectors of the economy with limited re-adjustments of production as a consequence of water availability constraints acting on water-intensive sectors. This outcome is expected since in this scenario the economies under study lack the ability to improve water productivity through a re-allocation of available resources. The AGLST allocation determines a neutral impact over non-food sectors and, depending on the exposure of the economies in water-scarce regions to food sectors (crops and food processing), determines a low impact on GDP, as non-crop water users act as free-riders. However, in the AGLST case, production of staple crops (rice, wheat, and other grains) is the most significantly impacted with important implications for food security. In the FRAGM variant, 
the separation of water uses by crop and non-crop users enables the availability of a guaranteed water volume for crops and therefore ensures some protection for food security. In this case, alterations to the crop production mix and changes in crop prices are the lowest. Nevertheless, FRAGM leads to higher GDP impacts as the divergence in marginal water productivity between crops and other sectors remains significant, as revealed by the fourfold difference between the water scarcity rents of the two user types. In the FULL case allowing full mobility of water resources across economic, the GDP and food security impacts are moderate relative to the other allocation methods.

\subsection{GDP Versus Food Security}

Table 4 summarises these findings and reveals two important contrasts in the incidence of water scarcity across the two dimensions of GDP and food security. The first contrast is between diversified economies (India and the Middle East) and those with a significant food sector in the regional GDP (South Asia). Economies with a sizeable agricultural and food processing sector do not show an important variation in GDP impacts across the three allocation methods based on water productivity differences (AGLST, FULL, FRAGM) - the drop in crop production has a significant negative knock-on effects over the other sectors which are not large enough to absorb the means of production released by agriculture. A similar conclusion was reached through the basin-level analysis in [34] and is a general indication of the lower labour productivity in agriculture as opposed to other sectors of the economy.

The second contrast applies to diversified economies and refers to the difference between the AGLST, FULL, and FRAGM methods and that of a more prescriptive allocation (LIMIT) where most water uses are pre-determined. For the former group of methods, the GDP-food security impacts are antisymmetric, producing either 'high-low', 'moderate-moderate' or 'low-high' outcomes. For the LIMIT method, the impacts are high across both dimensions. These observed trade-offs between GDP and food security make a case for a general equilibrium approach rather than a partial-crop-focused analysis. Water scarcity and the region-specific sectoral interlinkages lead to different outcomes depending on the allocation method used.

These trade-offs are essential in the discussion related to the impacts of water scarcity over prosperity. By taking into account only the GDP deviations from the baseline, it could be inferred that water deficits effects are not so much a matter of availability but one of how water resources are managed considering the relative water productivities of users. This conclusion is also coming out of the economic modelling results in [23] and is also captured here through the differences between LIMIT and the other three productivity-based methods. However, the results also reveal that the food security impacts are large and could be felt much more by the low-income household and by the rural population on whose livelihoods depend on crop production.

Table 4. GDP and food security impacts comparison across economy types by water allocation method.

\begin{tabular}{|c|c|c|c|c|c|c|}
\hline \multirow{2}{*}{ Economy Type } & \multicolumn{3}{|c|}{ GDP Impacts } & \multicolumn{3}{|c|}{ Food Security Impacts } \\
\hline & High & Moderate & Low & High & Moderate & Low \\
\hline Diversified economy & LIMIT, FRAGM & FULL & AGLST & LIMIT, AGLST & FULL & FRAGM \\
\hline Significant food production sectors & LIMIT & AGLST, FULL, FRAGM & $\mathrm{n} / \mathrm{a}$ & LIMIT, AGLST & FULL & FRAGM \\
\hline
\end{tabular}

\subsection{Drivers of GDP Impacts}

The economy-wide impacts of water scarcity are strongest in conditions of limited possibilities of water re-allocation across economic activities (LIMIT case) with values close to $2 \%$ of GDP for the Middle East and South Asia. The most affected areas are the self-abstracting sectors (crops, water distribution sectors, and thermal power), with cascading effects on the water-intensive industries supplied with industrial water (primary energy, chemicals, manufacturing, mining, and paper). However, livestock production is much less affected due to the sector's high water productivity compared to all other water users. The re-allocation of non-water factors of production (labour and 
capital) in sectors with low or no water inputs is limited with only singular cases of visible increases in output (generally non-thermal power).

Nevertheless, these negative effects are alleviated by the substitution effects which can occur between similar activities (irrigated and rainfed crop production, thermal and non-thermal power generation). Therefore, whilst the substitutability between varieties of market commodities remains valid (irrigated and rainfed crops could be considered homogenous and therefore close to perfect substitutes; thermal and non-thermal power can be imperfect substitutes as, for instance, thermal power technologies could be a more reliable solution for baseload power production whereas non-thermal (solar and wind) technologies produce electricity intermittently), the capacity of production to adjust over time especially in the power generation systems is important. The model assumes a perfect mobility of capital and labour. Hence, the switch in production from one type to another is frictionless. However, considering the long lifetime of power generation assets, the perfect mobility of capital could be challenged through a CET capital mobility specification. This imperfect mobility assumption could thus further increase the economic impacts of water scarcity over the overall power generation with knock-on effects across the other economic sectors. Future work could address more advanced sector-specific adaptation mechanisms e.g., a quicker transition to non-thermal power production given certain climate change objectives or a faster adoption of water-efficient cooling methods in thermal power generation.

Another alleviating factor is the household recycling of revenue of water rents-the loss of income due to a water-constrained economic activity is partially counterbalanced by an increase in income from scarcity rents. This revenue recycling is a different specification than that in [23] where water scarcity translates into a loss in total factor productivity across sectors based on the initial relative water productivities, and thus household income is generally reduced.

Another important determinant in GDP that also impacts welfare and food security is the combination of the distribution of baseline sectoral water productivities and the size of water demand in low productivity sectors. Regions with low productivity sectors also accounting for the largest share of withdrawals (India with rice and wheat, Northern Africa with other crops) make most of their water demand reductions in these activities. Therefore, the economic impacts are concentrated within a small number of crop growing activities leaving the other parts of the economy less water constrained. Again, the negative impacts on irrigated production are partially offset through substitution with rainfed production, and therefore the localised effects on a few economic activities are further attenuated.

The obtained changes in withdrawals to meet the sustainability threshold reflect both differences in water productivity and the adaptability of specific sectors to water deficits. Among the self-abstracting sectors (which treat water as a perfect complement to other inputs), livestock and thermal power see the lowest reduction in withdrawals as an indication of their low water intensity. At the same time, in spite of a superior water productivity, municipal water is a more important source of demand reduction than industrial water, marking the larger flexibility of the underlying municipal water users to substitute water with other inputs.

Notably in diversified economies, the size of GDP impacts is determined by the sectoral impacts of water-intensive industrial users. In the model specification, these sectors have a low substitutability of water with other inputs and factors. With an increased adaptability which can come from the adoption of more water-efficient production processes, the impacts could be significantly reduced as indicated by the results of a sensitivity analysis on the key elasticity of substitution between industrial water inputs and all other intermediate goods. Therefore, the magnitude of effects on economic activity in a scenario with a low flexibility in the technological choices warrants more research into the sectorand region-specific means of improving water productivity in industrial activities. An example of how the water savings potential varies between regions is given in ([35], p. 73). 


\subsection{Significance of International Trade}

The virtual water trade captured in this analysis goes beyond the standard assumption that, under water scarcity, trade from water-abundant to water-scarce areas would increase. It does this by overcoming an important limitation of previous water footprinting studies which do not include the opportunity costs and comparative advantage considerations of these changes in trade [36,37].

The attenuating effect of international trade on food availability is therefore limited. The simultaneous occurrence of water scarcity across regions leads even to an increase in water pressure by less water-productive sectors in some regions in favour of other regions e.g., due to the size of initial trade links, India expands its exports of irrigated crops to the Middle East impacting, thus, its own food security. Furthermore, trade is conditioned by the flexibility in switching consumption from domestic to foreign varieties, given the Armington specification of trade. Regions which already have a high share in imports of water-intensive commodities (Middle East and Northern Africa) benefit more from virtual water inflows, whilst regions being self-sufficient from a crop production standpoint have a limited import expansion.

\subsection{Comparison to Other Studies}

The GDP and EV impacts obtained in [23] are significantly higher than the results obtained in this study, with a GDP decline, for instance, at or well above $4 \%$ in the Middle East. An explanation for these differences consists in the much larger water deficits considered and is justified by higher unconstrained withdrawals in water-scarce regions by 2050. Another explanation is that in [23] there are relatively low means of endogenous adaptation to water scarcity as output is constrained by pre-determined changes in sectoral output driven by exogenous changes in total factor productivities. In RESCU-Water, as discussed above, the advanced specification of water uses and the substitution possibilities between varieties of the same commodity (rainfed and irrigated crops, thermal and non-thermal electricity) allow for more resilience of the regional economies to water scarcity.

In the static-comparative simulations using the GTAP-W1 model [22], regional water demand is reduced by only a small fraction, leading to much lower GDP and sectoral impacts. Only a few sectors across water-constrained regions exceed a negative impact of $1 \%$ (mainly crops). At the same time, similarly to RESCU-Water, the sectoral output results indicate a re-allocation of non-water resources across economic activities towards sectors with little or no supplied water inputs.

\subsection{Limitations}

Whilst the concomitant incidence of water deficits is determined for a number of regions, some other regions were not considered as water scarce due to their more localised water deficits (China, Southern Africa, USA, Australia). From a spatial perspective, while the basin-level analyses fall outside of the scope of this article given the complexity in understanding the geographical distribution of future water demand in a global context [38,39], it would be expected that the addition of production constraints from these regions (notably on the relatively immobile crop production sectors) would further deteriorate the food security prospects especially in the Middle East and also increase the obtained global GDP impacts.

From a temporal perspective, an improvement could be brought by considering the timing of withdrawals and the hydrological patterns of return flows. Most of the sectors deal with significant water inefficiencies e.g., less than half of water withdrawn for irrigation is actually consumed through evapotranspiration. Hence, an important question is whether downstream actors could use withdrawn but unconsumed volumes by upstream users. The inclusion of hydrological detail on the quantity and quality of the runoff and groundwater infiltration regarding return flows would enable a more accurate quantification of this potential from a time-of-use perspective.

Therefore, the coupling of RESCU-Water with other hydrological models comprising advancements regarding the spatially and temporally detailed information on the future water 
withdrawals constraints in relation to the topology of users could enable the inclusion of other regions in the analysis and would also allow for a further qualification of future sustainable withdrawal thresholds. On the hydrological side, this matter at a global scale is still work in progress $[3,38]$ as most similar approaches have so far focused on basin-level applications or on specific user categories [40] and only very recently across larger geographical scales [39].

Regarding the coverage of allocation methods, the model mostly makes use of differences in water productivities in re-distributing available water resources to the different users. At the same time, the different principles used allow for a prioritisation of certain users in the detriment of others. A further analysis could be conducted in the direction of food security policy by considering among other things programmes for increased irrigation water efficiency or a larger availability of water for crop production (possible through the FRAGM method used in this study by shifting the burden of reducing withdrawals to non-agricultural sectors). However, considering the global level of the analysis, it would be difficult at this stage to introduce other relevant methods which do not embed water productivity information but are mostly prescriptive in nature.

Another limitation is the absence of institutional and transactional costs that would be implied by water markets. Their inclusion would be more suitable for a national- or sub-national-level analysis in which the specific institutional arrangements could be properly taken into account.

\section{Conclusions}

This study used the future evolution of unconstrained water demand driven by socio-economic development as a starting point to determine the impacts of water deficits on economic activity, welfare, and food security. By comparing the unconstrained demands with regional thresholds for sustainable withdrawals, four regions emerged as water deficient due to their growth in water demand across five water user archetypes (irrigation, livestock, thermal cooling, industrial water, and municipal water)-India, South Asia, the Middle East, and Northern Africa. The reduction in water demand in these regions was enabled using four different water allocation methods.

Under the assumption of perfect water mobility, an allocation based on differences in water productivity between sectors leads theoretically to water allocative efficiency (FULL method). However, this does not guarantee the best aggregate economic outcome due to the interaction with other factors of production. Changes in sectoral output due to water scarcity also determine a re-allocation of non-water resources across the economy. With agriculture also having a low factor productivity of capital and labour, the water allocation methods determining the highest re-distribution of resources to the other sectors lead to the lowest GDP impacts. Therefore, the method treating crops as lowest water priority users (AGLST method) mostly improves the output prospects of non-food sectors to the detriment of crop production and food processing.

At the same time, the scale of economy-wide impacts are dependent on the size of sectors with low-water productivity (economic diversity), the size of water withdrawals in these sectors and the flexibility of important water users to substitute from water inputs in conditions of water scarcity. Furthermore, the use of international trade as means to alleviate the impacts of water deficits are conditional upon trade elasticities and the baseline import dependency of water-intensive commodities-the lower the ratio, the lower the changes in net imports of virtual water trade under water scarcity.

The food security impacts are pronounced across all methods considered, with the lowest negative outcomes obtained through the isolation of water demand in irrigation from all other water uses (FRAGM method). In the model simulations, this implied a uniform reduction in crop and non-crop water availability. More protection to the food value chain could be obtained by ensuring more water availability for crop production and less for other uses. However, this would implicitly lead to a higher negative GDP impact as a trade-off.

By using a comprehensive CGE framework focused on the economy-wide uses of freshwater, the results of this study offer an extended insight into the economic impacts of alternative water 
allocation regimes. The results presented here go beyond most of the previous work which focused on the relationship between water scarcity and agriculture and which only took one water management method into account $[17,18,41]$. Furthermore, the analysis outputs are an important expansion into the topic of trade-offs between aggregate economy-wide impacts and food security, an area underexplored even in the most recent economy-wide modelling work.

Supplementary Materials: The following are available online at http:/ /www.mdpi.com/2073-4441/10/10/1442/s1.

Author Contributions: Conceptualization, V.N.; Methodology. V.N.; Validation, V.N.; Formal Analysis, V.N.; Writing —Original Draft Preparation, V.N.; Writing—Review \& Editing, V.N. and M.W.; Visualization, V.N.

Funding: This research was funded through the UCL ISR PhD Programme on the Sustainable Use of Resources and the Environment (Victor Nechifor).

Acknowledgments: We would want to thank Paul Ekins and Alvaro Calzadilla for their valuable comments during the development of the study and the writing of this journal article. We are also grateful for the feedback and suggestions received from our reviewers.

Conflicts of Interest: The authors declare no conflict of interest. The funders had no role in the design of the study; in the collection, analyses, or interpretation of data; in the writing of the manuscript, and in the decision to publish the results.

\section{References}

1. International Energy Agency. World Energy Outlook 2012; International Energy Agency (IEA): Paris, France, 2012.

2. Marchal, V.; Dellink, R.; Van Vuuren, D.; Clapp, C.; Chateau, J.; Magné, B.; van Vliet, J. OECD Environmental Outlook to 2050; Organization for Economic Co-operation and Development (OECD): Paris, France, 2011.

3. Wada, Y.; Flörke, M.; Hanasaki, N.; Eisner, S.; Fischer, G.; Tramberend, S.; Satoh, Y.; van Vliet, M.T.H.; Yillia, P.; Ringler, C. Modeling global water use for the 21st century: Water Futures and Solutions (WFaS) initiative and its approaches. Geosci. Model Dev. 2016, 9, 175-222. [CrossRef]

4. World Economic Forum. Risk Report 2015; World Economic Forum (WEF): Cologny, Switzerland, 2015.

5. World Bank. High and Dry: Climate Change, Water, and the Economy; World Bank: Washington, DC, USA, 2016.

6. Organization for Economic Co-operation and Development. Water Resources Allocation; Organization for Economic Co-operation and Development (OECD): Paris, France, 2015.

7. Saleth, R.M. Water Markets in India: Extent and Impact. In Water Markets for the 21st Century; Springer: Dordrecht, The Netherlands, 2014; pp. 239-261.

8. Shiklomanov, I.A.; Balonishnikova, J.A. World water use and water availability: Trends, scenarios, consequences. Int. Assoc. Hydrol. Sci. Publ. 2003, 281, 358-364.

9. Vörösmarty, C.J.; Sahagian, D. Anthropogenic disturbance of the terrestrial water cycle. Bioscience 2000, 50, 753-765. [CrossRef]

10. Shen, Y.; Oki, T.; Kanae, S.; Hanasaki, N.; Utsumi, N.; Kiguchi, M. Projection of future world water resources under SRES scenarios: An integrated assessment. Hydrol. Sci. J. 2014, 59, 1775-1793. [CrossRef]

11. Wada, Y.; Bierkens, M.F. Sustainability of global water use: Past reconstruction and future projections. Environ. Res. Lett. 2014, 9, 104003. [CrossRef]

12. Hejazi, M.; Edmonds, J.; Chaturvedi, V.; Davies, E.; Eom, J. Scenarios of global municipal water-use demand projections over the 21st century. Hydrol. Sci. J. 2013, 58, 519-538. [CrossRef]

13. Shen, Y.; Oki, T.; Utsumi, N.; Kanae, S.; Hanasaki, N. Projection of future world water resources under SRES scenarios: Water withdrawal. Hydrol. Sci. J. 2008, 53, 11-33. [CrossRef]

14. Rosegrant, M.W.; Cai, X.; Cline, S.A. World Water and Food to 2025: Dealing with Scarcity; International Food Policy Research Institute (IFPRI): Washington, DC, USA, 2002.

15. Lotze-Campen, H.; Müller, C.; Bondeau, A.; Rost, S.; Popp, A.; Lucht, W. Global food demand, productivity growth, and the scarcity of land and water resources: A spatially explicit mathematical programming approach. Agric. Econ. 2008, 39, 325-338. [CrossRef]

16. Calzadilla, A.; Rehdanz, K.; Tol, R.S. The economic impact of more sustainable water use in agriculture: A computable general equilibrium analysis. J. Hydrol. 2010, 384, 292-305. [CrossRef] 
17. Liu, J.; Hertel, T.; Taheripour, F. Analyzing future water scarcity in computable general equilibrium models. Water Econ. Policy 2016, 2, 1650006. [CrossRef]

18. Ponce, R.; Parrado, R.; Stehr, A.; Bosello, F. Climate Change, Water Scarcity in Agriculture and the Economy-Wide Impacts in a CGE Framework; FEEM Working Paper No. 79.2016; Fondazione Eni Enrico Mattei (FEEM): Venice, Italy, 2016.

19. Winchester, N.; Kirby, L.; Strzepek, K.M.; Reilly, J.M. The impact of water scarcity on food, deforestation and bioenergy. In Proceedings of the 2016 GTAP Conference, Washington, DC, USA, 15-17 June 2016.

20. Organization for Economic Co-operation and Development. The Land-Water-Energy Nexus; Organization for Economic Co-operation and Development (OECD): Paris, France, 2017.

21. Darwin, R. Effects of greenhouse gas emissions on world agriculture, food consumption, and economic welfare. Clim. Chang. 2004, 66, 191-238. [CrossRef]

22. Berrittella, M.; Hoekstra, A.Y.; Rehdanz, K.; Roson, R.; Tol, R.S. The economic impact of restricted water supply: A computable general equilibrium analysis. Water Res. 2007, 41, 1799-1813. [CrossRef] [PubMed]

23. Roson, R.; Damania, R. The macroeconomic impact of future water scarcity: An assessment of alternative scenarios. J. Policy Model. 2017, 39, 1141-1162. [CrossRef]

24. Rodell, M.; Velicogna, I.; Famiglietti, J.S. Satellite-based estimates of groundwater depletion in India. Nature 2009, 460, 999. [CrossRef] [PubMed]

25. Wada, Y.; van Beek, L.P.; van Kempen, C.M.; Reckman, J.W.; Vasak, S.; Bierkens, M.F. Global depletion of groundwater resources. Geophys. Res. Lett. 2010, 37. [CrossRef]

26. Van Vuuren, D.P.; Kriegler, E.; O’Neill, B.C.; Ebi, K.L.; Riahi, K.; Carter, T.R.; Edmonds, J.; Hallegatte, S.; Kram, T.; Mathur, R.; et al. A new scenario framework for climate change research: Scenario matrix architecture. Clim. Chang. 2014, 122, 373-386. [CrossRef]

27. Nechifor, V.; Winning, M. Projecting irrigation water requirements across multiple socio-economic development futures-A global CGE assessment. Water Resour. Econ. 2017, 20, 16-30. [CrossRef]

28. Peters, J.C. The GTAP-Power Data Base: Disaggregating the Electricity Sector in the GTAP Data Base; Department of Agricultural Economics, Purdue University: West Lafayette, IN, USA, 2016.

29. Fischer, G.; Hizsnyik, E.; Prieler, S.; Wiberg, D. Scarcity and Abundance of Land Resources: Competing Uses and the Shrinking Land Resource Base; Food and Agriculture Organization (FAO): Rome, Italy, 2011.

30. Siebert, S.; Döll, P. Quantifying blue and green virtual water contents in global crop production as well as potential production losses without irrigation. J. Hydrol. 2010, 384, 198-217. [CrossRef]

31. Roobavannan, M.; van Emmerik, T.H.; Elshafei, Y.; Kandasamy, J.; Sanderson, M.R.; Vigneswaran, S.; Pande, S.; Sivapalan, M. Norms and values in sociohydrological models. Hydrol. Earth Syst. Sci. 2018, 22, 1337-1349. [CrossRef]

32. Berrittella, M.; Rehdanz, K.; Tol, R.S.; Zhang, J. The impact of trade liberalization on water use: A computable general equilibrium analysis. J. Econ. Integr. 2008, 23, 631-655. [CrossRef]

33. Alcamo, J.; Döll, P.; Henrichs, T.; Kaspar, F.; Lehner, B.; Rösch, T.; Siebert, S. Global estimates of water withdrawals and availability under current and future "business-as-usual" conditions. Hydrol. Sci. J. 2003, 48, 339-348. [CrossRef]

34. Roobavannan, M.; Kandasamy, J.; Pande, S.; Vigneswaran, S.; Sivapalan, M. Allocating environmental water and impact on basin unemployment: Role of a diversified economy. Ecol. Econ. 2017, 136, 178-188. [CrossRef]

35. McKinsey, S. Charting Our Water Future: Economic Framework to Inform Decision Making; 2030 Water Resources Group: Washington, DC, USA, 2009.

36. Wichelns, D. Virtual water: A helpful perspective, but not a sufficient policy criterion. Water Resour. Manag. 2010, 24, 2203-2219. [CrossRef]

37. Wichelns, D. Volumetric water footprints, applied in a global context, do not provide insight regarding water scarcity or water quality degradation. Ecol. Indic. 2017, 74, 420-426. [CrossRef]

38. van Vuuren, D.P.; Lucas, P.L.; Hilderink, H. Downscaling drivers of global environmental change: Enabling use of global SRES scenarios at the national and grid levels. Glob. Environ. Chang. 2007, 17, 114-130. [CrossRef]

39. Kahil, T.; Parkinson, S.; Satoh, Y.; Greve, P.; Burek, P.; Veldkamp, T.I.; Burtscher, R.; Byers, E.; Djilali, N.; Fischer, G.; et al. A continental-scale hydro-economic model for integrating water-energy-land nexus solutions. Water Resour. Res. 2018. [CrossRef] 
40. Flörke, M.; Kynast, E.; Bärlund, I.; Eisner, S.; Wimmer, F.; Alcamo, J. Domestic and industrial water uses of the past 60 years as a mirror of socio-economic development: A global simulation study. Glob. Environ. Chang. 2013, 23, 144-156. [CrossRef]

41. Calzadilla, A.; Rehdanz, K.; Betts, R.; Falloon, P.; Wiltshire, A.; Tol, R.S. Climate change impacts on global agriculture. Clim. Chang. 2013, 120,357-374. [CrossRef] 